Article

\title{
Amphiphilic Block Copolymers with Vinyl Caprolactam as Kinetic Gas Hydrate Inhibitors
}

\author{
Faraz Rajput, Milan Maric $\mathbb{D}$ and Phillip Servio *(D) \\ Department of Chemical Engineering, McGill University, Montreal, QC H3A 0G4, Canada; \\ faraz.rajput@mail.mcgill.ca (F.R.); milan.maric@mcgill.ca (M.M.) \\ * Correspondence: phillip.servio@mcgill.ca
}

check for updates

Citation: Rajput, F.; Maric, M.;

Servio, P. Amphiphilic Block Copolymers with Vinyl Caprolactam as Kinetic Gas Hydrate Inhibitors. Energies 2021, 14, 341. https:// doi.org/10.3390/en14020341

Received: 15 December 2020 Accepted: 5 January 2021 Published: 9 January 2021

Publisher's Note: MDPI stays neutral with regard to jurisdictional clai$\mathrm{ms}$ in published maps and institutional affiliations.

Copyright: $(\odot 2021$ by the authors. Licensee MDPI, Basel, Switzerland. This article is an open access article distributed under the terms and conditions of the Creative Commons Attribution (CC BY) license (https:// creativecommons.org/licenses/by/ $4.0 /)$.

\begin{abstract}
Macrosurfactants consisting of water-soluble poly(vinylcaprolactam) (PVCap) or poly (vinylpyrrolidone) (PVP) segments with comparatively shorter hydrophobic poly(styrene) (PS) or poly(2,3,4,5,6-pentafluorostyrene) (PPFS) segments were used as kinetic hydrate inhibitors (KHIs). These were synthesized with 2-cyanopropan-2-yl N-methyl-N-(pyridin-4-yl)dithiocarbamate switchable reversible addition-fragmentation chain transfer (RAFT) agent at $60^{\circ} \mathrm{C}$ or $90^{\circ} \mathrm{C}$ for $1-\mathrm{P}(\mathrm{S} / \mathrm{PFS})$ or 1-PVCap, respectively, followed by chain extension at $90^{\circ} \mathrm{C}$ or $70{ }^{\circ} \mathrm{C}$ with PVCap or PVP, respectively. The addition of PVCap to the pure methane-water system resulted in a 53\% reduction of methane consumption (comparable to PVP with 51\% inhibition) during the initial growth phase. A PS-PVCap block copolymer comprised of $10 \mathrm{~mol} \%$ PS and $90 \mathrm{~mol} \%$ PVCap improved inhibition to 56\% compared to the pure methane-water system with no KHIs. Substituting PS with a more hydrophobic PPFS segment further improved inhibition to $73 \%$. By increasing the ratio of the hydrophobic PS- to PVCap-groups in the polymer, an increase of its inhibition potential was measured. For PPFS-PVCap, an increase of PPFS ratio from $5 \%$ to $10 \%$ decreased the methane formation rate by $6 \%$. However, PPFS-PVCap block copolymers with more than $20 \mathrm{~mol} \%$ PPFS were unable to dissolve in water due to increase in hydrophobicity and the attendant low critical micelle concentration (CMC).
\end{abstract}

Keywords: amphiphilic block copolymer; kinetic hydrate inhibitors; switchable reversible additionfragmentation chain transfer (RAFT) agent

\section{Introduction}

Under thermodynamic conditions of high pressure and low temperature, when free water molecules are present along with small gas molecules such as nitrogen, methane, and carbon dioxide, water may form a thermodynamically stable water lattice structure. This stable water lattice structure forms a crystalline solid called gas hydrates [1]. The guest gas molecules are trapped within the cavities while the water cage is held together through hydrogen bonding and stabilized by Van der Waals interactions with the guest molecule. While there are situations where the formation of gas hydrate can be beneficial, such as gas sequestration processes or gas transportation [2], there are other instances where the formation of gas hydrates can be problematic depending on their location. In gas pipelines, for example, the formation of gas hydrates is undesirable as it may lead to the formation of plugs which can hinder the flow [3]. These hydrate plugs become damaging to the pipelines themselves and to other equipment downstream, and potentially leading to environmental disasters [4]. Consequently, the prevention of gas hydrate formation becomes increasingly important. The oil and gas industries rely on using alcohols and electrolytes to prevent the formation of gas hydrates in pipelines [5]. The thermodynamic conditions for forming these hydrates are changed by adding high quantities of alcohols to the pipelines [6,7], however due to the large costs associated with the thermodynamic inhibition of gas hydrate formation, increasing interest is going towards the development of kinetic inhibitors. These low-dosage hydrate inhibitors delay the onset of nucleation and slow the growth rate of 
crystals [8]. They require much lower amounts $(<1 \mathrm{wt} \%)$ within the flow, which lowers their operational costs and downstream separation costs [9]. One of the commonly accepted mechanisms for kinetic inhibition is the adsorption of kinetic hydrate inhibitors (KHIs) onto the hydrate crystal surface to reduce the surface area available for water to enter the hydrate phase $[10,11]$. To be effective, KHIs require high solubility in water as well as the ability to adsorb well to the polar surface of hydrate crystals [12]. The effectiveness of KHIs can further increase if these polymers have hydrophobic properties [8,13]. Since the gases forming clathrates are hydrophobic, KHIs with hydrophobic head groups allow them to migrate near the liquid-gas interface and inhibit hydrate formation sooner [14]. The requirement of these properties has led to the use of certain vinyl-based polymers, with functional groups having high tendencies for hydrogen bonding [9]. Determining the effects of variables, such as the molecular weight (size) of these KHIs as well as their amphiphilic properties, on the inhibition potential of gas hydrates is crucial as this information can be used to improve the kinetic inhibitors currently being used by the industry and increase their efficiency.

\section{Micellization and the Critical Micelle Concentration (CMC)}

One of the important aspects of the colloidal properties of block copolymers is the ability to micellize in selective solutions. If the block copolymer is dissolved in a thermodynamically favorable solvent for one of the blocks of the copolymer while being a non-solvent for the other block of the copolymer, it may form micellar aggregates [15]. These micelle structures are typically formed of a tight core of insoluble blocks with a more flexible outer core of soluble blocks [16]. The critical micelle concentration (CMC) is defined by the concentration after which the addition of more block copolymer surfactants appears directly as micellar aggregates [17]. Figure 1 illustrates the formation of micellar aggregates of block copolymers. The addition of block copolymers in water begins forming aggregates as the concentration increases and reaches closer to the CMC. The hydrophobic, insoluble, end blocks of the block copolymer begin aggregating and form a swollen core while the soluble end forms a larger, filamented, outer core. As the purpose of the block copolymer surfactants as KHIs is to adsorb onto the growing hydrate crystal, it is desirable for these block copolymers to be far enough away from their CMC in order to prevent aggregates from forming and be able to adsorb onto a larger surface [14]. The CMC is therefore an important factor to consider when synthesizing and optimizing KHIs. CMC measurements are not currently widely been considered when synthesizing or using low dosage KHIs for methane inhibition. This research aims at emphasizing the importance of this measurement as well as laying an important groundwork for CMC measurements of macromolecules.

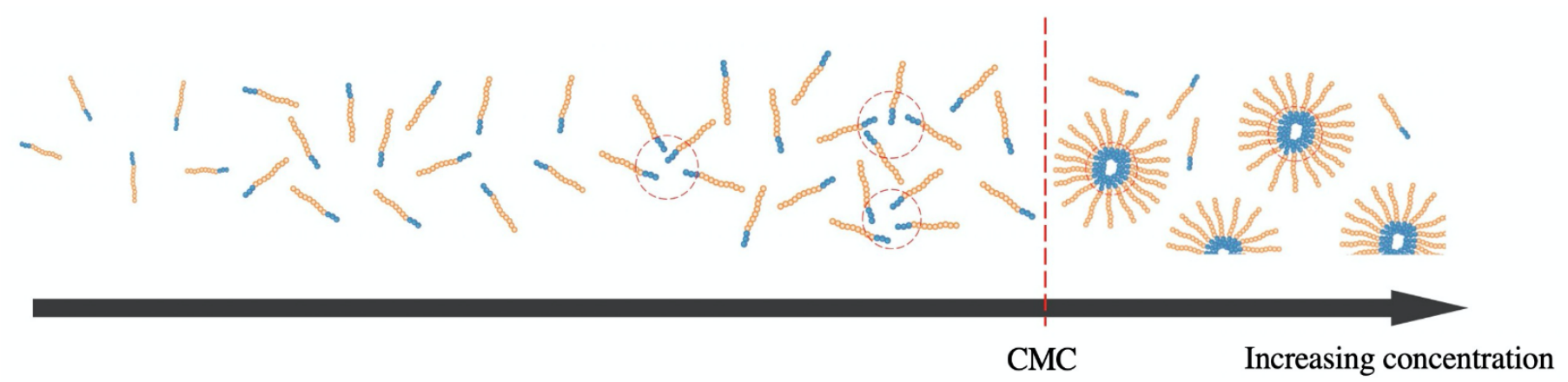

Figure 1. Illustration of micellar aggregate forming with increasing concentrations. The blue end is the insoluble block end while the orange is the soluble block end.

We earlier examined water-soluble poly(vinylpyrrolidone) (PVP) and poly(vinylalcohol) (PVA) diblock copolymers with short hydrophobe caps consisting of poly(styrene) (PS) or poly(pentafluorostyrene) (PPFS). We were able to incorporate blocks with quite different 
polymerization behavior (vinyl esters like vinyl acetate (VAc), the precursor for vinylalcohol, and VP known as one of the less activated monomers (LAMs) with monomers like styrene, which are known as more activated monomers (MAMs) into a single diblock copolymer using reversible addition fragmentation transfer polymerization (RAFT). This latter method combines the ability of an active chain end to be re-initiated to form a second block, a trait that is typically observed by living polymerization methods, but using an essentially radical polymerization process, with the more relaxed purification and reaction conditions. Further, RAFT, like other reversible de-activation radical polymerization (RDRP) processes, can combine monomers that would be otherwise impossible by living polymerization methods. We found that the block copolymers were extremely effective as KHIs in particularly low dosages. Building on this, we continue our study with VCap block/random copolymers due to the many reports of PVCap being an effective hydrate inhibitor. Our report here is the first to use PVCap block copolymers as KHIs.

\section{Materials and Methods}

\subsection{Materials}

$N$-vinylcaprolactam (VCap monomer, $>98.0 \%$, stabilized with $~ 20$ ppm HO-TEMPO; Millipore Sigma-Aldrich, Oakville, Canada), $>99 \%$, contains 3-20 ppm hydroquinone inhibitor, Millipore Sigma-Aldrich), 2,3,4,5,6-pentafluorostyrene (PFS monomer), 99\%, contains $0.1 \%$ inhibitor, Millipore Sigma-Aldrich), styrene (S monomer, 99.9\%, ReagentPlus; Sigma-Aldrich), 2-Cyanopropan-2-yl $N$-methyl- $N$-(pyridin-4-yl) carbamodithioate (switchable RAFT agent, $>97 \%$, Millipore Sigma-Aldrich), azo bis-isobutyrylnitrile (AIBN), $\mathrm{N}, \mathrm{N}$-dimethylformamide ( $>95 \%$, certified ACS, Acros Organics, Fair Lawn, United States), tetrahydrofuran (THF, $>99.9 \%$, high-performance liquid chromatography [HPLC] grade; Fisher Scientific, Waltham, United States), reverse osmosis purified $\mathrm{H}_{2} \mathrm{O}$ was used as received, trifluoromethanesulfonic acid ( $>99 \%$, ReagentPlus; MilliporeSigma-Aldrich). The methane gas used for hydrate growth experiments was obtained from MEGS Inc. (Montreal, Canada) with ultra-high purity in excess of $99.99 \%$.

\subsection{Synthesis of Macro Chain Transfer Agent (Macro CTA) and Subsequent Chain Extension}

For this study, block copolymers consisting of short PS and PPFS chains along with comparatively longer chains of PVCap, and PVP, are synthesized in order to test their performance as kinetic methane hydrate inhibitors. Figure 2 illustrates the reaction mechanism used for the synthesis of the block copolymers. Macro chain transfer agents (macro-CTAs) of 1-PS, 1-PPFS, and 1-PVCap are first synthesized using a 2-cyanopropan-2-yl N-methyl$N$-(pyridin-4-yl)dithiocarbamate switchable RAFT agent.

These macro-CTAs are then extended with VCap and VP to form block copolymers of various molecular weights and hydrophobic to hydrophilic block ratios. Table 1 summarizes the reaction conditions for synthesizing 1-poly(styrene) (1-PS), 1-poly(2,3,4,5,6pentafluorostyrene) (1-PPFS), and 1-poly(vinyl caprolactam) (1-PVCap) macro chaintransfer agents. While 1-PS and 1-PPFS macro-CTAs have been previously synthesized and reported by us [14], the reaction conditions have been modified in order to achieve lower dispersities with the intention of better control of microstructure and are reported in Table 1.

Following the successful synthesis of the macro-CTA, a chain extension synthesis reaction is carried out with VCap monomer in order to form the desired block copolymer polymer. Table 2 lists the experimental reaction conditions for the chain extension reactions. 


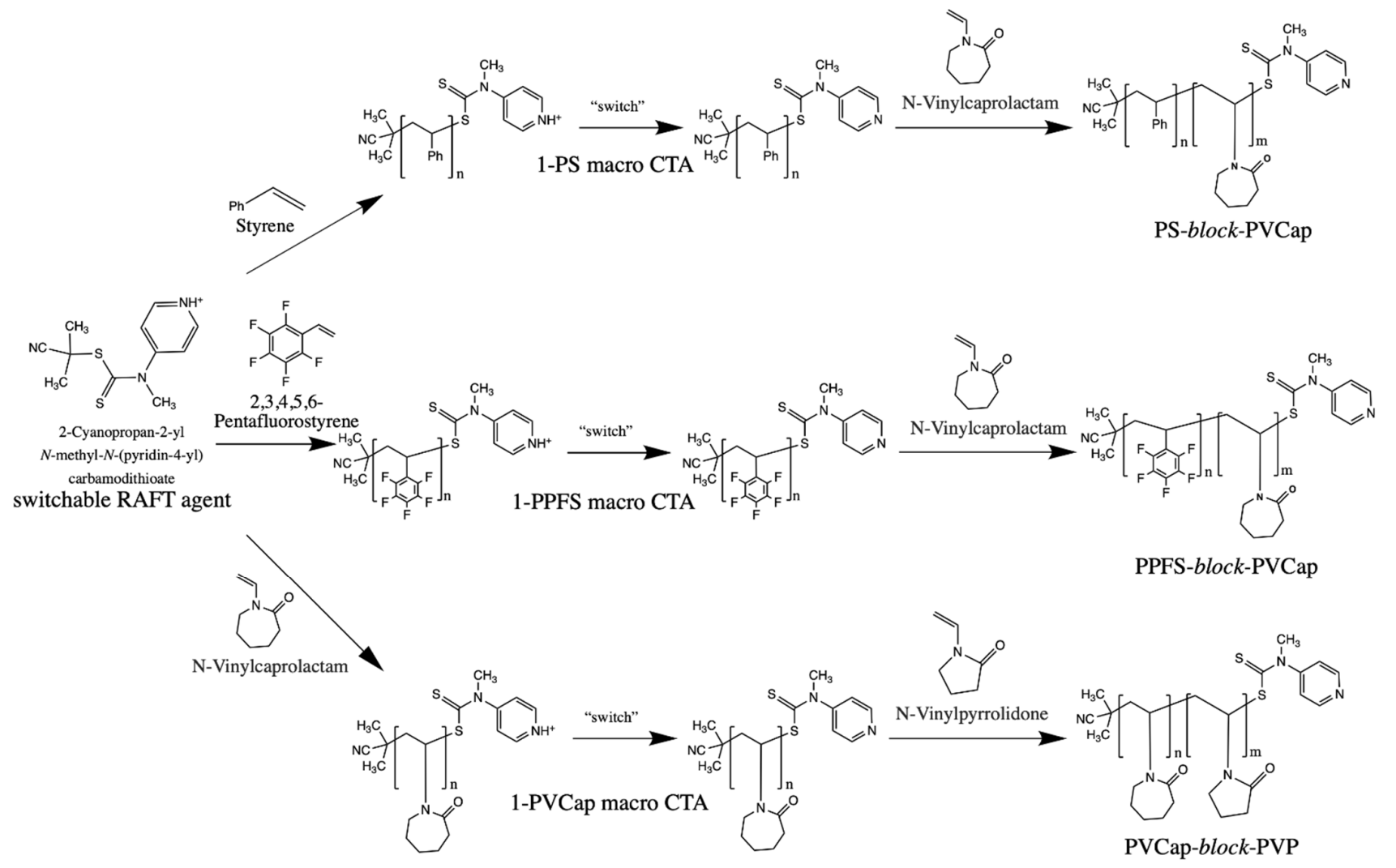

Figure 2. Reaction scheme for synthesis of (less activated monomer (LAM))-block-(more activated monomer (MAM)) copolymers used as kinetic hydrate inhibitors (KHIs). Monomers of styrene, 2,3,4,5,6-pentafluorostyrene, or N-Vinylcaprolactam are first synthesized with a switchable RAFT agent to form a macro chain-transfer agent (CTA). The CTA is then extended with $\mathrm{N}$-Vinylcaprolactam, or N-Vinylpyrrolidone after having been switched to its deprotonated form.

Table 1. Experimental reaction conditions for polymerization of 1-poly(styrene) (1-PS), 1-poly(2,3,4,5,6-pentafluorostyrene) (1-PPFS), and 1-poly(vinyl caprolactam) (1-PVCap) macro chain-transfer agent.

\begin{tabular}{|c|c|c|c|c|}
\hline Experiment ID & Monomer & Reaction Temperature & $\begin{array}{c}\text { Reaction Duration a } \\
\text { (min) }\end{array}$ & $\begin{array}{c}M_{n, t h} \\
\left(\mathrm{~kg} \mathrm{~mol}^{-1}\right)^{b}\end{array}$ \\
\hline 1-PS & styrene & $60^{\circ} \mathrm{C}$ & 300 & 10 \\
\hline 1-PPFS & $\begin{array}{c}2,3,4,5,6- \\
\text { pentafluorostyrene }\end{array}$ & $60{ }^{\circ} \mathrm{C}$ & 300 & 10 \\
\hline 1-PVCap & vinyl caprolactam & $90{ }^{\circ} \mathrm{C}$ & 180 & 10 \\
\hline
\end{tabular}

a The 'reaction duration' is how long the reaction lasted before it was stopped in order to achieve the desired polymer MW. These reactions were not run until $100 \%$ monomer conversion. ${ }^{b} \mathrm{M}_{\mathrm{n} \text {,th }}$ represents the molecular weight of the polymer expected to achieve at $100 \%$ conversion of the monomer.

Table 2. Experimental reaction conditions for chain extension polymerization reactions of 1-PS, 1-PPFS, and 1-PVCap with $N$-vinylcaprolactam (VCap) and $N$-vinylpyrrolidone (VP).

\begin{tabular}{|c|c|c|c|c|c|}
\hline Experiment ID & $\begin{array}{l}\text { Macro Chain-Transfer Agent } \\
\left.\text { (Mn }\left[\mathrm{kg} \mathrm{mol}^{-1}\right], \oplus\right)\end{array}$ & Monomer $^{b}$ & $\begin{array}{c}\text { Reaction } \\
\text { Temperature }\end{array}$ & $\begin{array}{c}\text { Reaction } \\
\text { Duration (h) }\end{array}$ & $\begin{array}{c}\text { Target MW } \\
\mathrm{M}_{\mathrm{n}, \mathrm{th}}\left(\mathrm{kg} \mathrm{mol}^{-1}\right)\end{array}$ \\
\hline PS-PVCap & 1-PS $(4.8,1.39)$ & VCap & $90^{\circ} \mathrm{C}$ & 3 & 80 \\
\hline PPFS-PVCap & 1-PPFS $(4.7,1.41)$ & VCap & $90{ }^{\circ} \mathrm{C}$ & 3 & 80 \\
\hline PVCap-PVP & 1-PVCap $(5.3,1.52)$ & $\mathrm{VP}$ & $70{ }^{\circ} \mathrm{C}$ & 3 & 100 \\
\hline
\end{tabular}

${ }^{a}$ Indicates the macro chain-transfer agent used in the chain extension reaction. Mn and $Đ$ (values in parenthesis) represent the number average molecular weight and the dispersity of the synthesized macro chain-transfer agent used to chain extend. These were calculated using gel permeation chromatography. ${ }^{b}$ The monomer used for chain extension. ${ }^{c}$ Expected molecular weight (MW) if $100 \%$ monomer conversion is achieved. 
Figure 3 shows the molecular weight distributions of the 1-PPFS macro-CTA as well as for its chain extended product with PVCap to form a PPFS-PVCap block copolymer. The monomodal distributions are indicative of a clean chain extension with no apparent un-reacted CTA.

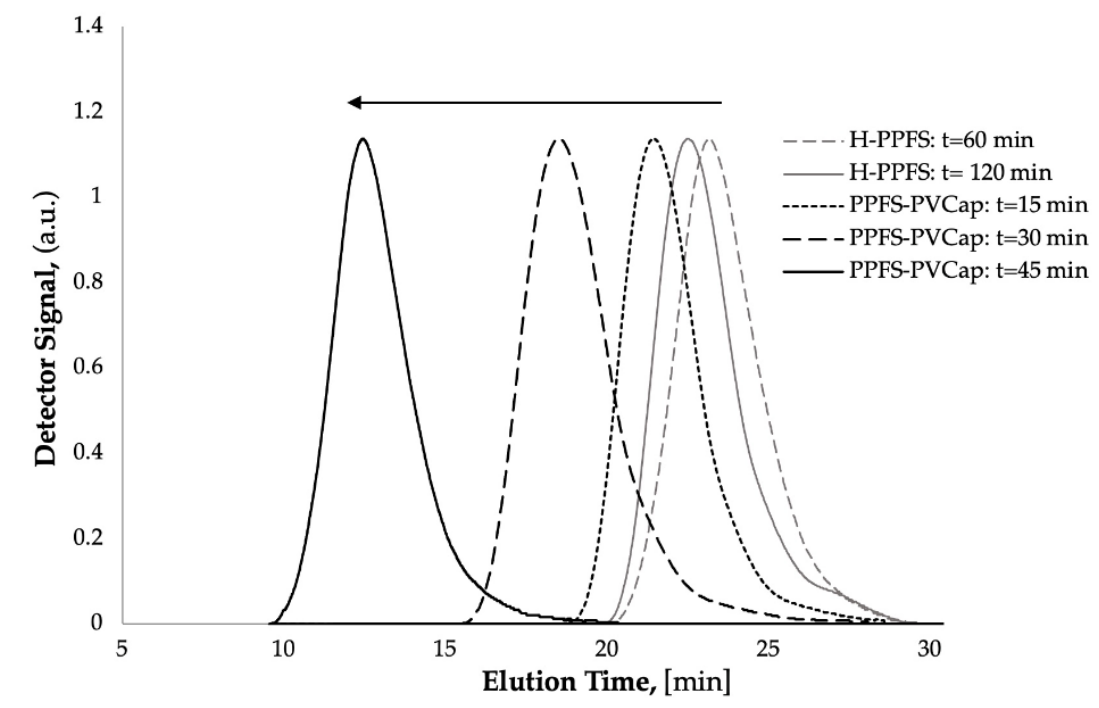

Figure 3. GPC chromatograms for synthesis of 1-PPFS macro-CTA followed by its subsequent chain extension with PVCap to form block copolymer PPFS-PVCap. H-PPFS indicates the homopolymer macro-CTA.

\subsection{Characterization}

\subsection{1. ${ }^{1} \mathrm{H}-\mathrm{NMR}$}

${ }^{1} \mathrm{H}-\mathrm{NMR}$ measurements were performed using a $500 \mathrm{MHz}$ Varian Mercury NMR. The samples were dissolved in deuterated dimethyl sulfoxide (DMSO) solvent. The conversions of the monomers were determined by examining the ratio of the area associated with the vinylic protons in the monomer disappearing (5-6 ppm), relative to the rest of the protons in the monomer, as the reactions progressed. The ${ }^{1} \mathrm{H}-\mathrm{NMR}$ spectra of PPFS-PVCap is shown in Figure 4. The gel permeation chromatography (GPC) plot (Figure 3) indicated that there is no unreacted macro-CTA left. Additionally, the NMR plot shows that there is no more unreacted monomer (no vinyl peaks of the monomer at 5-6 ppm). Therefore, within the detection limits, there is more than $99 \%$ copolymer, and no evidence of unreacted monomer.

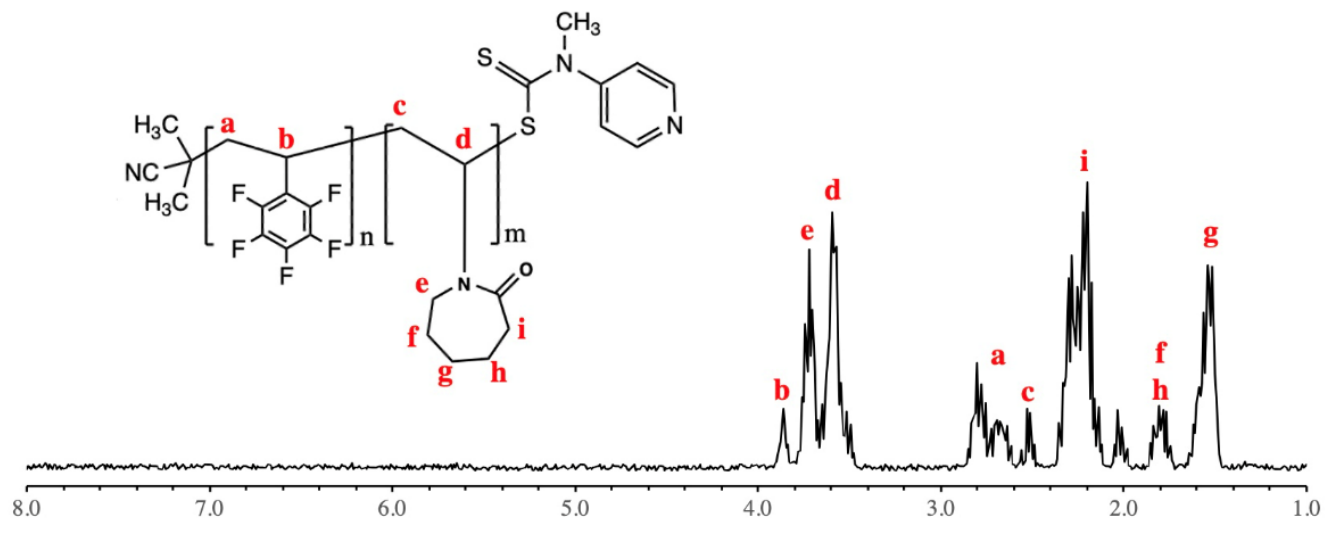

Figure 4. ${ }^{1} \mathrm{H} \mathrm{NMR}\left(\mathrm{CDCl}_{3}\right)$ of PPFS-PVCap block copolymer. 


\subsubsection{CMC}

As the concentration of the block copolymer in solution increases, aggregates begin forming and the surface charge decreases. Once the CMC is passed and all further block copolymers added go into the micellar aggregate, a constant, low surface charge is expected. The surface charge measurement as a means for $\mathrm{CMC}$ determination has more recently been used with higher molecular weight copolymers and shown to be an effective method [14,18]. Varying concentrations (100 ppm, 200 ppm, 400 ppm, 800 ppm, 1600 ppm, 3200 ppm, $7000 \mathrm{ppm}, 14,000 \mathrm{ppm}, 28,000 \mathrm{ppm}$, and $56,000 \mathrm{ppm}$ ) of the synthesized polymers were prepared. One-milliliter solutions were placed in a disposable capillary cell and inserted into the ZetaSizer. The surface (zeta potential) charge was measured using the ZetaSizer Nano ZS by Malvern. An electrical field (E) of $4.9 \pm 0.1 \mathrm{~V}$ was applied at $25^{\circ} \mathrm{C}$ to measure the estimated surface charge. The concentration at which the surface charge goes from decreasing to a constant low charge is reported as the block copolymers CMC.

\subsubsection{Hydrate Growth Experiments}

The experimental setup used for methane hydrate kinetic inhibition studies was described by Bergeron et al. $[19,20]$. The detailed setup and protocol are presented in Rajput et al. [14]. Briefly, 700 ppm of the block copolymer macrosurfactant is dissolved in deionized water and $300 \mathrm{~mL}$ of this solution is added to a crystalizing reactor chamber. The reactor is left overnight to equilibrate at $277.15 \mathrm{~K}$. Once the temperature has equilibrated, the reactor pressure is increased to $4735 \mathrm{kPa}$ using methane gas. This pressure brings the system operating conditions to above the equilibrium point of hydrates with $4{ }^{\circ} \mathrm{C}$ of driving force. Stirring is started to begin the hydrate formation reaction and the pressure changes are monitored in order to determine the amount of gas consumed by the reactor to form methane hydrates. When the system reaches the onset of nucleation, a linear consumption of gas is observed due to the linear nature of crystallization growth. This linear consumption marks the beginning of the hydrate growth phase, and data are collected for the first $1500 \mathrm{~s}$ as initial growth rates.

\section{Results and Discussion}

\subsection{Synthesis of 1-PS, 1-PPFS, and 1-PVCap Macro-CTAs}

In order to form the desired block copolymer macrosufactants, the first step involved the synthesis of macro-CTAs. Hydrophobic monomers of styrene and 2,3,4,5,6pentafluorostyrene were used as precursors for the synthesis of the macro-CTAs. Additionally, more hydrophilic vinyl caprolactam was also used to form a macro-CTA. Table 3 indicates the molecular weights and dispersities of the macro-CTAs synthesized by following the experimental conditions presented in Table 1.

Table 3. Identification of the macro-CTAs (mCTA) synthesized.

\begin{tabular}{|c|c|c|c|}
\hline Experiment ID & $\begin{array}{c}\text { Monomer Conversion } \\
(\%)\end{array}$ & $\begin{array}{l}\text { Overall } \mathrm{MW}^{\mathrm{b}} \\
\left(\mathrm{M}_{\mathrm{n}}, \mathrm{kg} \mathrm{mol}^{-1}\right)\end{array}$ & Đ \\
\hline PS mCTA & 45.1 & 4.6 & 1.37 \\
\hline PPFS mCTA & 43.5 & 4.8 & 1.42 \\
\hline PVCap mCTA & 44.3 & 5.1 & 1.47 \\
\hline
\end{tabular}

${ }^{a}$ The monomer conversion (\%) was calculated using ${ }^{1} \mathrm{H}-\mathrm{NMR}$ where the area corresponding to the ${ }^{1} \mathrm{H}$ protons of the monomers in the solution was measured and compared against the area corresponding to the monomers in the polymer. ${ }^{b}$ Overall MW represents the number average molecular weight of the synthesized macro chain-transfer agent used to chain extend with the second batch of monomer. These were calculated using gel permeation chromatography.

The kinetics of the polymerization reaction for the synthesis of PVCap macro-CTA is shown in Figure 5. The monomer conversion is plotted on a semi-logarithmic scale to extract the apparent rate constant from the slope. We see in Figure 5A a linear progression on the semi-logarithmic scale, as expected, indicating a first-order growth of the polymer 
as the monomer is converted to polymer. We also observe a linear progression of molecular weight with conversion, as seen on Figure 5C. As the conversion of the monomer reaches $50 \%$ and higher, a slight deviation from the linear growth was observed due to the higher rate of undesired irreversible termination and chain transfer reactions occurring in the bulk of the solution. This deviation is expected to further rise as reaction times are increased, however the reactions for the synthesis of macro-CTAs were stopped at lower conversions $(<50 \%)$ to maintain high chain end fidelity and obtain polymers with predictable molecular weights and low dispersities (seen in Figure 5B).
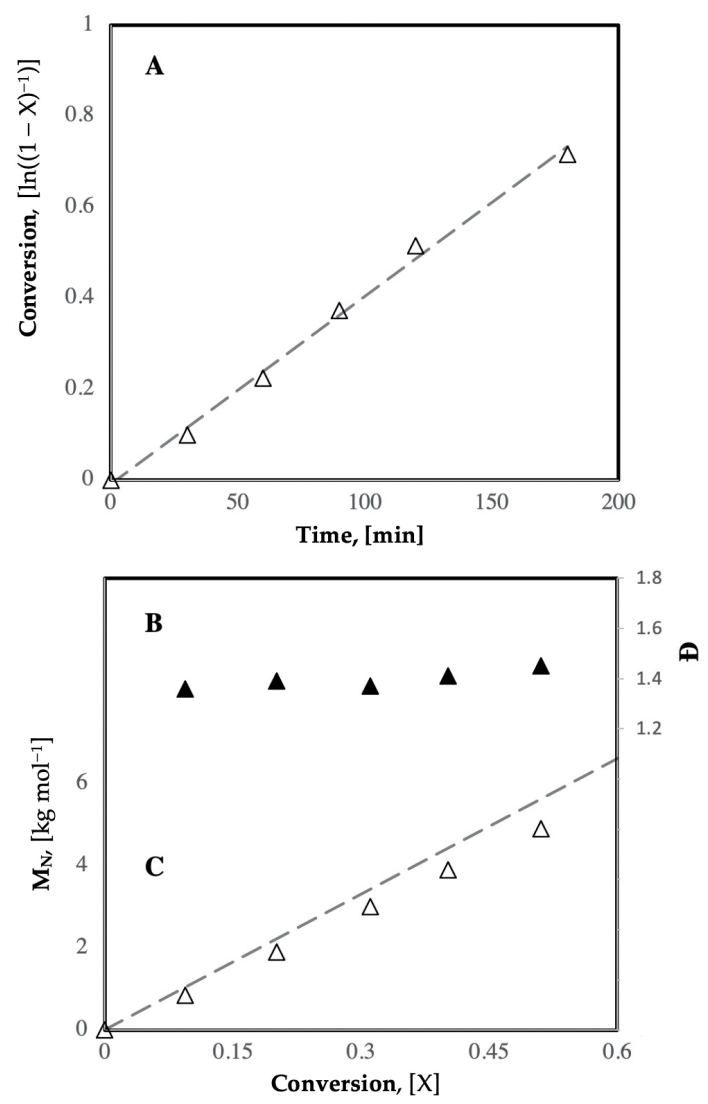

Figure 5. (A) Plots of the linearized conversion $\left[\ln (1-\mathrm{X})^{-1}\right](\mathrm{X}=$ conversion $)$ versus time at $90^{\circ} \mathrm{C}$; (B) the dispersity $(Đ)$ versus conversion $(X) ;(C)$ the number average molecular weight $\left(\mathrm{M}_{\mathrm{N}}\right)$ versus conversion $(\mathrm{X})$ for the polymerization of vinylcaprolactam.

From Figure 5, the apparent rate constant for the homopolymerization of PVCap is calculated to be $7.1 \times 10^{-3} \mathrm{~min}^{-1}$. This rate constant is lower than the rate constant for the homopolymerization of PVP under similar conditions [14,21,22].

\subsection{Chain Extension of 1-PS and 1-PPFS with VCap}

In order to obtain the desired block copolymer macrosurfactants for hydrate inhibition experiments, the aforementioned macro-CTAs were chain extended with VCap to form the desired block copolymers. A first-order growth of the polymer was observed, as indicated by the linear fit to the data on the semi-logarithmic plot of conversion over time shown in Figure 6A. Similarly, a linear progression of molecular weight with conversion was seen for lower monomer conversions $(<50 \%)$ and slight deviations that are generally expected at higher conversions due to irreversible side and termination reactions (Figure 6C). 

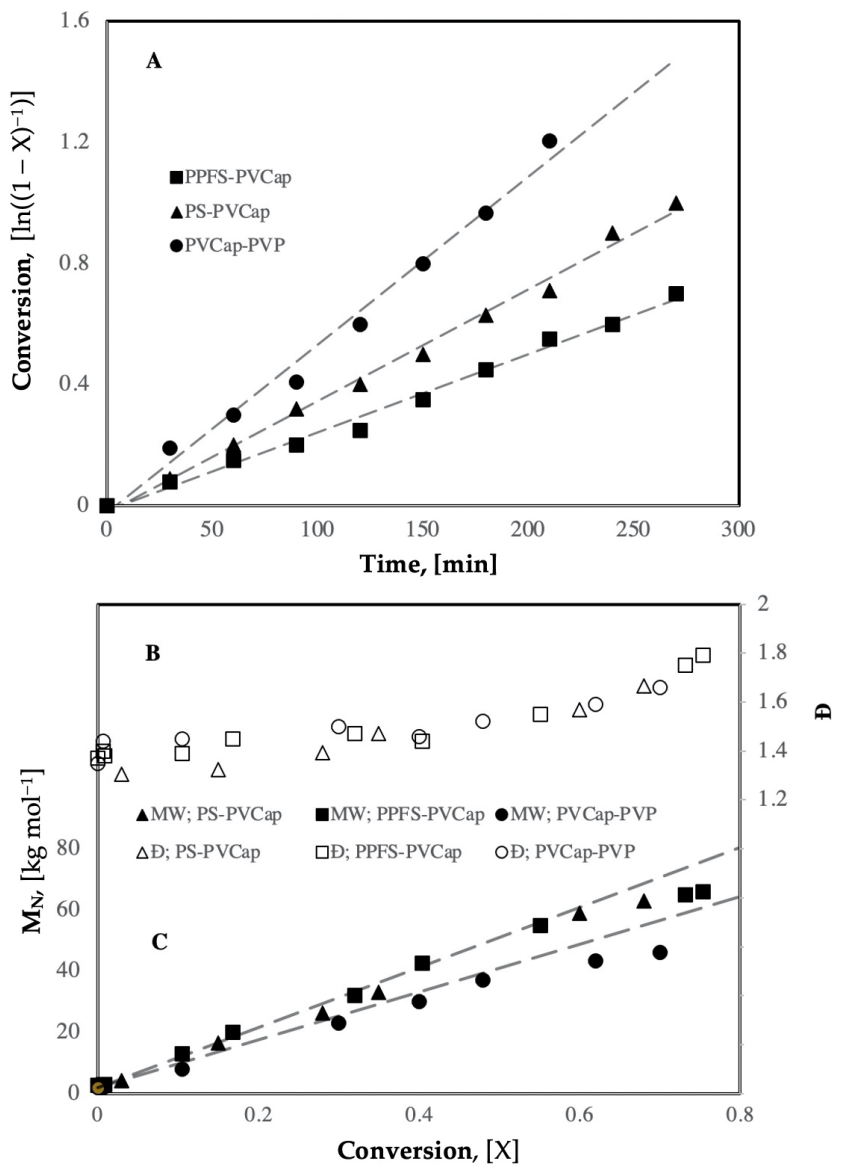

Figure 6. (A) Plots of the linearized conversion $\left[\ln (1-X)^{-1}\right](X=$ conversion $)$ versus time at $90{ }^{\circ} \mathrm{C}$ for PVCap, and $70{ }^{\circ} \mathrm{C}$ for PVP; (B) the dispersity (Đ) versus conversion (X); $(\mathrm{C})$ the number average molecular weight $\left(\mathrm{M}_{\mathrm{N}}\right)$ versus conversion $(\mathrm{X})$ for the chain extension reaction.

The apparent rate constants for the chain extension reactions of PS-PVCap, PPFSPVCap, and PVCap-PVP were calculated to be $4.9 \times 10^{-3} \mathrm{~min}^{-1}, 3.9 \times 10^{-3} \mathrm{~min}^{-1}$, and $2.5 \times 10^{-3} \mathrm{~min}^{-1}$, respectively.

Table 4 indicates the final molecular weights and dispersities of the block copolymer macrosurfactants synthesized. The macro-CTAs were chain-extended for varying reaction times following the kinetic curves shown in Figure 6 in order to achieve the desired mole fractions of the macro-CTA in the polymer.

Table 4. Identification of the block copolymers synthesized for determination of critical micelle concentration (CMC) and kinetic hydrate inhibition studies.

\begin{tabular}{|c|c|c|c|c|}
\hline Experiment ID ${ }^{a}$ & $\begin{array}{c}\text { Overall MW } \\
\left(\mathrm{M}_{\mathrm{n}}, \mathrm{kg} \mathrm{mol}^{-1}\right)\end{array}$ & $\begin{array}{c}\text { Mole Fraction of Macro CTA in Polymer } \\
\text { [PS, PPFS, PVCap] }\end{array}$ & Đ & $\begin{array}{l}\text { MW of Macro CTA in Polymer } \\
\text { [PS, PPFS, PVCap] }\left(\mathrm{M}_{\mathrm{n}}, \mathrm{kg} \mathrm{mol}^{-1}\right)\end{array}$ \\
\hline PS-PVCap(0.05) & 77.1 & 0.06 & 1.39 & 4.6 \\
\hline PS-PVCap (0.10) & 42.6 & 0.11 & 1.41 & 4.6 \\
\hline PS-PVCap $(0.20)$ & 23.9 & 0.19 & 1.42 & 4.6 \\
\hline PPFS-PVCap(0.05) & 90.5 & 0.05 & 1.45 & 4.8 \\
\hline PPFS-PVCap $(0.10)$ & 46.2 & 0.10 & 1.50 & 4.8 \\
\hline PPFS-PVCap(0.15) & 30.0 & 0.16 & 1.52 & 4.8 \\
\hline PPFS-PVCap (0.20) & 23.8 & 0.20 & 1.53 & 4.8 \\
\hline PVCap-PVP(0.10) & 53.1 & 0.10 & 1.50 & 5.1 \\
\hline PVCap-PVP(0.20) & 28.0 & 0.18 & 1.55 & 5.1 \\
\hline
\end{tabular}

a The experiment ID indicates the hydrophilic and hydrophobic monomers present in the block copolymer. The term AA-BB(0.xx) is used to describe block copolymers where AA is the hydrophobic end group of the polymer (PS, PPFS, or PVCap), BB is the hydrophilic end group (PVCap or PVP), and (0.xx) is the mole fraction of the hydrophobic monomer in the copolymer as measured by ${ }^{1} \mathrm{H}-\mathrm{NMR}$. 


\section{3. $C M C$}

Having synthesized block copolymers with the purpose of inhibiting the formation of gas hydrates, knowing the extent by which a polymer surfactant has micellized in solution becomes crucial as it impacts the ability on how the polymers interact with the surrounding hydrates. Studies have shown that the overall molecular weight of a polymer has a much greater impact on this CMC [23] than the hydrophobic end group [24-26]. Our study observed a similar trend, whereby block copolymers with a higher overall molecular weight [experiment ID $x x-x x(0.05)]$ had a lower CMC than shorter block copolymers [experiment ID xx-xx(0.20)]. When comparing block copolymers of comparable molecular weight in Table 5, we see PPFS-containing block copolymers exhibit lower CMC than PScontaining block copolymer due to its stronger hydrophobic properties. A block copolymer comprising 25\% PS and 75\% PVCap (PS-PVCap(0.25), albeit being comparatively short in terms of molecular weight, was not water-soluble and therefore the CMC is not reported.

Table 5. Critical micelle concentration (CMC) of synthesized block copolymers.

\begin{tabular}{cc}
\hline Experiment ID & CMC $\left(\times \mathbf{1 0}^{-\mathbf{4}} \mathbf{M}\right)$ \\
\hline PS-PVCap(0.05) & 2.9 \\
PS-PVCap $(0.10)$ & 4.0 \\
PS-PVCap $(0.20)$ & 7.0 \\
PS-PVCap(0.25) & - \\
PPFS-PVCap(0.05) & 1.3 \\
PPFS-PVCap(0.10) & 3.7 \\
PPFS-PVCap(0.15) & 4.9 \\
PPFS-PVCap(0.20) & 6.0 \\
PVCap-PVP(0.10) & 45.9 \\
PVCap-PVP(0.20) & 58.0 \\
\hline
\end{tabular}

\subsection{Methane Hydrate Growth}

During methane hydrate growth experiments, as the stirring in the reactor is started and the experiment begun, we observe an initially high dissolution rate of the methane gas into the water/macrosurfactant solution. Over time, this dissolution rate decreases as the solution saturates. At the onset of nucleation, the methane hydrates are beginning to form and consume the methane in the solution allowing for more gas to dissolve into the liquid. As the hydrate growth crystallization process is linear, we observe a linear consumption of gas, an indication of the beginning of the hydrate formation process. The data collected for the initial growth rate of hydrate crystals are presented below in Figure 7.

Figure 8 shows the initial growth rates of methane hydrates in deionized water as well as with the addition of PVP and PVCap homopolymer inhibitors. We observe a methane consumption rate of $1.14 \times 10^{-5} \mathrm{~mol} \mathrm{~s}^{-1}$ for the aqueous system with no added inhibitors. This consumption rate was observed previously [14,27]. With the addition of PVP, we observe a $51 \%$ reduction in growth rate of hydrates with a methane consumption rate of $0.56 \times 10^{-5} \mathrm{~mol} \mathrm{~s}^{-1}$. Conversely, by adding PVCap homopolymer as inhibitor, a $53 \%$ reduction in growth rate of hydrate is observed (methane consumption rate of $0.54 \times 10^{-5} \mathrm{~mol} \mathrm{~s}^{-1}$ ). While both homopolymers exhibit comparable hydrate inhibition properties, PVCap shows more inhibition potential due to its stronger hydrophobic tendencies. 


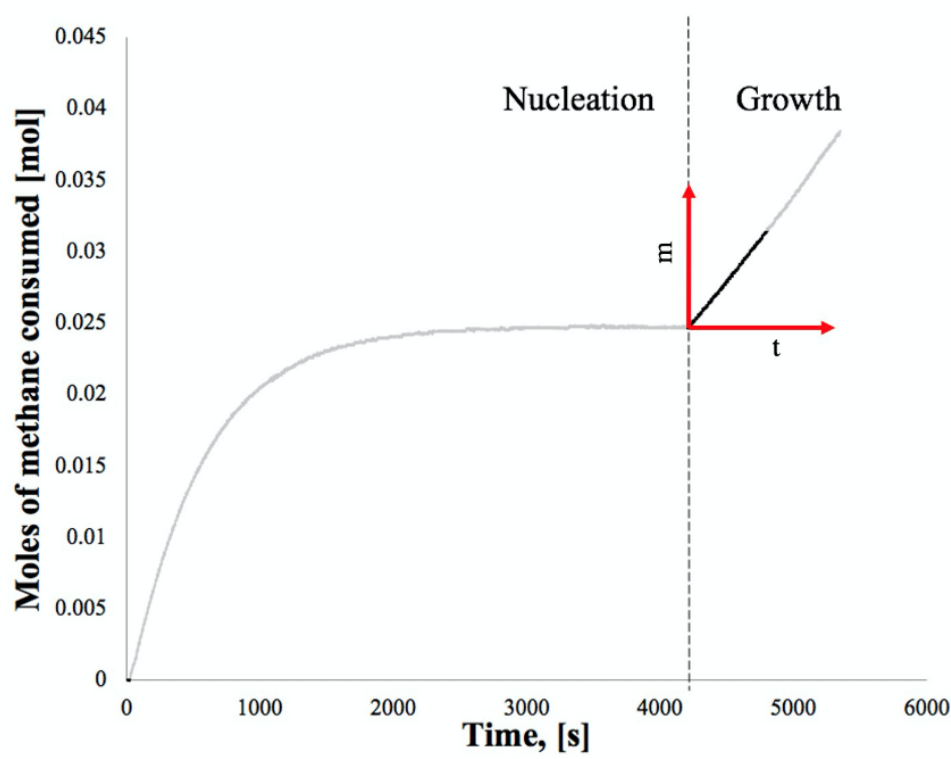

Figure 7. Expected curve obtained during hydrate growth experiments.

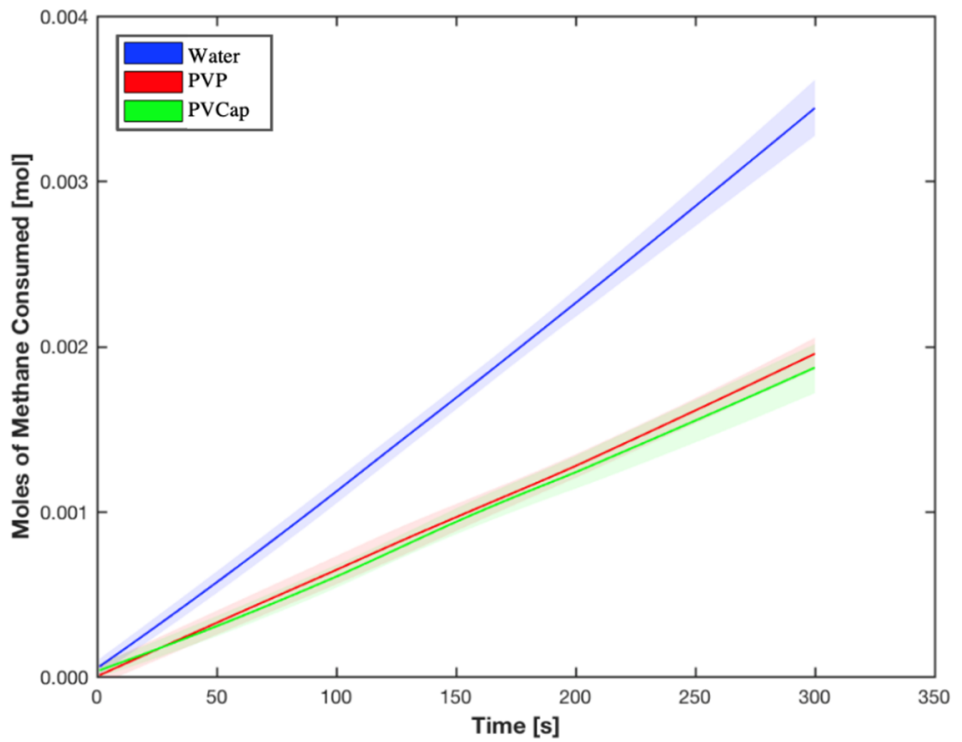

Figure 8. Initial growth rate of methane hydrates in water with PVP and PVCap homopolymer surfactants. The shaded area corresponding to each color is the $95 \%$ confidence interval for each polymer; 5-10 replicates of each experimental conditions were performed.

While poly(vinyl alcohol), a hydrophilic homopolymer kinetic inhibitor, does show methane hydrate inhibitory properties, it is not as strong of an inhibitor as PVP and PVCap homopolymers, with reduction in growth rate of hydrates of $25 \%$, compared to $51 \%$ and $53 \%$ for PVP and PVCap as seen in Figure 9.

Comparing PVA inhibition with PVP and PVCap, it is apparent that the hydrophobic properties of the R-group of PV-R block copolymers are important. To further increase the hydrophobicity of the inhibitor, a hydrophobic PS-end group was added to the PVCap homopolymer. PS-PVCap block copolymer exhibited a reduction of hydrate growth rate of $56 \%$, higher than both PVP and PVCap homopolymers. Similarly, substituting the PS-end group with a more hydrophobic PPFS-end group, showed an even further decrease in methane consumption rate and therefore increased inhibition effect. A methane consumption rate of $0.31 \times 10^{-5} \mathrm{~mol} \mathrm{~s}^{-1}$ (73\% inhibition) was calculated for the PPFS-PVCap block 
copolymer inhibitor. The addition of the PVCap-PVP block copolymer was comparable to PVCap and PS-PVCap with a 59\% inhibition of hydrate formation and did not show hydrate inhibition properties as pronounced as PPFS-PVCap. This clearly states that an amphiphilic block copolymer is critical for improved hydrate inhibition.

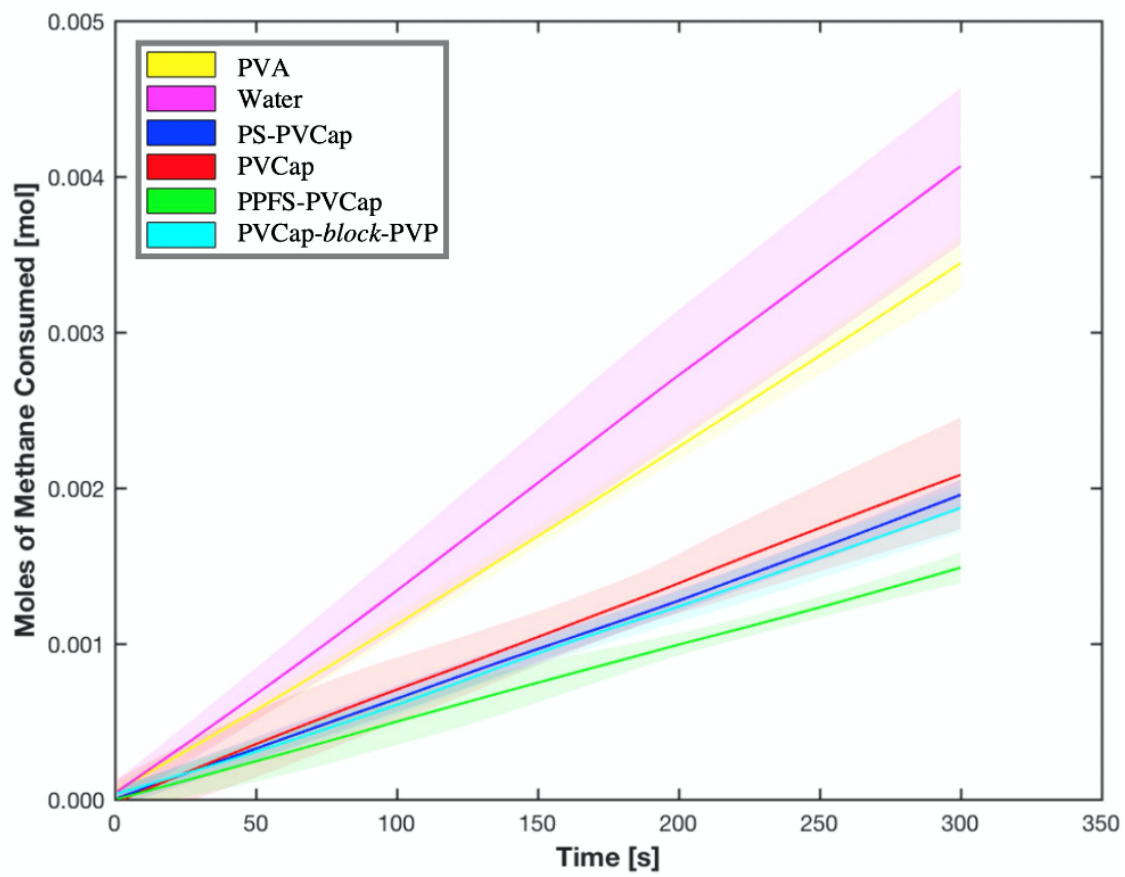

Figure 9. Initial growth rate of methane hydrates in water with PVA, PVCap, PS-PVCap, PPFSPVCap, andPVCap-PVP block copolymer surfactants. The shaded area corresponding to each color is the $95 \%$ confidence interval for each polymer; 5-10 replicates of each experimental conditions were performed.

In order to further investigate the effect of the hydrophobicity of the block copolymer end groups on the inhibition potential, block copolymers of PS-PVCap with the PS-end group composition ranging from $5 \%$ to $25 \%$ of the overall molecular weight, as well as PPFSPVCap with the PPFS-end group composition ranging from $5 \%$ to $20 \%$, were synthesized and tested. Comparing PS-PVCap block copolymers from Table 6, we observed a decrease in methane consumption rate with an increase of hydrophobic PS-end group composition in the block copolymer. This decreasing methane consumption rate corresponded to an increase in hydrate inhibition percentage from 50\% for PS-PVCap $(0.05)$ to $56 \%$ for PS-PVCap (0.10). It further increased to $61 \%$ for PS-PVCap $(0.20)$ and up to $65 \%$ for PSPVCap $(0.25)$. While these polymers have varying overall molecular weights, the molecular weight was previously shown to not have a substantial effect on the macrosurfactant's inhibition potential $[14,27,28]$. The observed change in methane consumption rates for these polymers is primarily due to the increased hydrophobic properties of the block copolymer. A similar trend is seen in the PPFS-PVCap block copolymer with increasing hydrophobic PPFS-end group. Increasing the PPFS to PVCap ratio from $5 \%$ to $10 \%$ shows a $6 \%$ increase in hydrate inhibition potential (going from $67 \%$ to $73 \%$ ). Although we expected this inhibition effect to further increase at 15\% PPFS, this was not observed (72\% hydrate inhibition). In fact, a slight decrease was measured, indicating the block copolymer was losing its inhibition effect. This is due to the much higher hydrophobicity of the block copolymer resulting in an increase of micellization, due to decreasing CMC. Furthermore, increasing the PPFS to PVCap ratio to $20 \%$ made the block copolymer insoluble in water. Finally, varying the PVCap to PVP ratio in the PVCap-PVP block copolymer did not contribute to an increase in inhibition effects. A decrease of hydrate inhibition of $2 \%$ was seen when going from 10\% PVCap to 20\% PVCap. This is due to the similar structures and 
inhibition potentials of PVP and PVCap, further underscoring that a distinct amphiphilic block copolymer was necessary for improved inhibition.

Table 6. Methane consumption rates and inhibition percentages for various block copolymer macrosurfactants.

\begin{tabular}{ccc}
\hline Experiment ID & $\begin{array}{c}\text { Methane Consumption Rate } \\
\left(\times \mathbf{1 0}^{-\mathbf{5}} \mathbf{\mathbf { m o l ~ } ^ { - 1 } \mathbf { ) }}\right.\end{array}$ & $\begin{array}{c}\text { Hydrate Inhibition Percentage } \\
\mathbf{( \% )}\end{array}$ \\
\hline Water & 1.14 & - \\
PS-PVCap(0.05) & 0.57 & 50 \\
PS-PVCap(0.10) & 0.50 & 56 \\
PS-PVCap(0.20) & 0.44 & 61 \\
PS-PVCap(0.25) & 0.40 & 65 \\
PPFS-PVCap(0.05) & 0.38 & 67 \\
PPFS-PVCap(0.10) & 0.31 & 73 \\
PPFS-PVCap(0.15) & 0.32 & 72 \\
PPFS-PVCap(0.20) & - & - \\
PVCap-PVP(0.10) & 0.47 & 59 \\
PVCap-PVP(0.20) & 0.49 & 57 \\
\hline
\end{tabular}

\section{Conclusions}

This paper reports the use of poly(vinyl caprolactam) (PVCap)-based amphiphilic block copolymers as kinetic hydrate inhibitors. The PVCap block copolymers were made using the 2-cyanopropan-2-yl N-methyl-N-(pyridin-4-yl)dithiocarbamate switchable RAFT agent. Macro chain-transfer agents (CTA) of 1-poly(styrene) (PS), 1-poly(2,3,4,5,6pentafluorostyrene) (PPFS), and 1-poly(vinyl caprolactam) (PVCap) were synthesized and then successfully chain extended with PVCap or PVP to synthesize block copolymers with amphiphilic properties. The critical micelle concentration was measured and shown to decrease with increasing molecular weights. In block copolymers of similar molecular weights, the CMC was seen to decrease for increasingly hydrophobic block copolymers.

These synthesized block copolymers were dissolved in deionized water and used as low-dosage kinetic hydrate inhibitors for methane hydrates. PVP and PVCap homopolymers showed a comparable $51 \%$ and $53 \%$ reduction of hydrate formation, respectively. By adding a hydrophobic PS- end group to the PVCap, a reduction in hydrate formation of $56 \%$ was observed, which was further increased to $73 \%$ by substituting PS- with a more hydrophobic PPFS- end group. Additionally, by increasing the hydrophobic length (PSend group) in the block copolymer (i.e., $5 \%$ to $20 \%$ overall molecular weight of PS end group with $95 \%$ to $80 \%$ PVCap), an increase in inhibition potential was observed due to the increase in hydrophobicity of the block copolymer. A similar trend was observed for PPFS-PVCap whereby increasing the PPFS- block from $5 \%$ to $10 \%$ of the overall molecular weight showed an increase in inhibition (decrease in methane consumption rate). Further increasing the hydrophobicity by increasing the PS or PPFS block length resulted in block copolymers that could not be dissolved in water, therefore losing its inhibition potential. A PVCap-PVP block copolymer was also synthesized and tested for its methane hydrate inhibition potential, however it was not shown to be much more effective than the PVCap or PVP homopolymers.

Author Contributions: Conceptualization, F.R., M.M., and P.S.; methodology, F.R.; validation, F.R., M.M., and P.S.; formal analysis, F.R.; investigation, F.R.; resources, F.R., M.M., and P.S.; data curation, F.R.; writing—original draft preparation, F.R.; writing—review and editing, F.R., M.M., and P.S.; visualization, M.M. and P.S.; supervision, M.M. and P.S.; project administration, F.R., M.M., and P.S.; funding acquisition, P.S. All authors have read and agreed to the published version of the manuscript.

Funding: This research was funded by NSERC Discovery Grants, grant number 288125 and FOAPAL number 278240 .

Institutional Review Board Statement: Not applicable. 
Informed Consent Statement: Not applicable.

Data Availability Statement: Data available in a public accessible repository.

Conflicts of Interest: The authors declare no conflict of interest.

\section{References}

1. Sloan, E.D.; Koh, C. Clathrate Hydrates of Natural Gases, 3rd ed.; CRC Press: Boca Raton, FL, USA, 2008.

2. Sloan, E.D. Fundamental principles and applications of natural gas hydrates. Nat. Cell Biol. 2003, 426, 353-359. [CrossRef] [PubMed]

3. Hammerschmidt, E.G. Formation of Gas Hydrates in Natural Gas Transmission Lines. Ind. Eng. Chem. 1934, 26, 851-855. [CrossRef]

4. Crone, T.J.; Tolstoy, M. Magnitude of the 2010 Gulf of Mexico Oil Leak. Science 2010, 330, 634. [CrossRef] [PubMed]

5. Mokhatab, S.; Wilkens, R.J.; Leontaritis, K.J. A Review of Strategies for Solving Gas-Hydrate Problems in Subsea Pipelines. Energy Sources Part A Recover. Util. Environ. Eff. 2007, 29, 39-45. [CrossRef]

6. Sun, C.; Chen, G.; Guo, T. Study of hydrate inhibition in multi-phase pipelines. Tianranqi Gongye Nat. Gas Ind. $2003,5,105-108$.

7. Anderson, F.E.; Prausnitz, J.M. Inhibition of gas hydrates by methanol. AIChE J. 1986, 32, 1321-1333. [CrossRef]

8. Perrin, A.; Musa, O.M.; Steed, J.W. The chemistry of low dosage clathrate hydrate inhibitors. Chem. Soc. Rev. 2013, 42, 1996-2015. [CrossRef]

9. Koh, C.A. Towards a fundamental understanding of natural gas hydrates. Chem. Soc. Rev. 2002, 31, 157-167. [CrossRef]

10. Ree, L.; Kelland, M.A.; Haddleton, D.M.; Alsubaie, F. Comparison of the Kinetic Hydrate Inhibition Performance of Block and Statistical N-Alkylacrylamide Copolymers. Energy Fuels 2017, 31, 1355-1361. [CrossRef]

11. King, H.E.; Hutter, J.L.; Lin, M.Y.; Sun, T. Polymer conformations of gas-hydrate kinetic inhibitors: A small-angle neutron scattering study. J. Chem. Phys. 2000, 112, 2523-2532. [CrossRef]

12. Reyes, F.T.; Kelland, M.A.; Kumar, N.; Jia, L. First Investigation of the Kinetic Hydrate Inhibition of a Series of Poly( $\beta$-peptoid)s on Structure II Gas Hydrate, Including the Comparison of Block and Random Copolymers. Energy Fuels 2015, $29,695-701$. [CrossRef]

13. Lederhos, J.; Long, J.; Sum, A.; Christiansen, R.; Sloan, E. Effective kinetic inhibitors for natural gas hydrates. Chem. Eng. Sci. 1996, 51, 1221-1229. [CrossRef]

14. Rajput, F.; Colantuoni, A.; Bayahya, S.; Dhane, R.; Servio, P.; Marić, M. Poly(styrene/pentafluorostyrene)-block-poly(vinyl alcohol/vinylpyrrolidone) amphiphilic block copolymers for kinetic gas hydrate inhibitors: Synthesis, micellization behavior, and methane hydrate kinetic inhibition. J. Polym. Sci. Part A Polym. Chem. 2018, 56, 2445-2457. [CrossRef]

15. Piirma, I. Polymeric Surfactants; Informa UK Limited: Colchester, UK, 2012.

16. Riess, G. Micellization of block copolymers. Prog. Polym. Sci. 2003, 28, 1107-1170. [CrossRef]

17. Ruckenstein, E.; Nagarajan, R. Critical micelle concentration. Transition point for micellar size distribution. J. Phys. Chem. 1975, 79, 2622-2626. [CrossRef]

18. Song, Y.; Sun, R.; Zhao, K.; Pan, X.; Zhou, H.; Li, D. An induction current method for determining the critical micelle concentration and the polarity of surfactants. Colloid Polym. Sci. 2015, 293, 1525-1534. [CrossRef]

19. Bergeron, S.; Servio, P. Reaction rate constant of CO2hydrate formation and verification of old premises pertaining to hydrate growth kinetics. AIChE J. 2008, 54, 2964-2970. [CrossRef]

20. Bergeron, S.; Servio, P. Reaction rate constant of propane hydrate formation. Fluid Phase Equilibria 2008, 265, 30-36. [CrossRef]

21. Benaglia, M.; Chen, M.; Chong, Y.K.; Moad, G.; Rizzardo, E.; Thang, S.H. Polystyrene-block-poly(vinyl acetate) through the Use of a Switchable RAFT Agent. Macromolecules 2009, 42, 9384-9386. [CrossRef]

22. Junkers, T.; Voll, D.; Barner-Kowollik, C. Determination of vinyl acetate propagation rate coefficients via high frequency pulsed laser polymerization. Polymers 2009, 9, 931-938. [CrossRef]

23. Yoshida, E. Control of Micellar Size and Critical Micelle Concentration for "Nonamphiphilic" Poly(vinyl phenol)-blockPolystyrene Diblock Copolymers. Polym. J. 2003, 35, 965-971. [CrossRef]

24. Zana, R. Dimeric and oligomeric surfactants. Behavior at interfaces and in aqueous solution: A review. Adv. Colloid Interface Sci. 2002, 97, 205-253. [CrossRef]

25. Nakayama, M.; Okano, T. Polymer Terminal Group Effects on Properties of Thermoresponsive Polymeric Micelles with Controlled Outer-Shell Chain Lengths. Biomacromolecules 2005, 6, 2320-2327. [CrossRef] [PubMed]

26. Otulakowski, Ł.; Gadzinowski, M.; Slomkowski, S.; Basinska, T.; Forys, A.; Dworak, A.; Trzebicka, B. Micellisation of polystyreneb-polyglycidol copolymers in water solution. Eur. Polym. J. 2018, 99, 72-79. [CrossRef]

27. Posteraro, D.; Ivall, J.; Maric, M.; Servio, P. New insights into the effect of polyvinylpyrrolidone (PVP) concentration on methane hydrate growth. 2. Liquid phase methane mole fraction. Chem. Eng. Sci. 2015, 126, 91-98. [CrossRef]

28. Erfani, A.; Varaminian, F.; Muhammadi, M. Gas Hydrate Formation Inhibition Using Low Dosage Hydrate Inhibitors. In Proceedings of the 2nd National Iranian Conference on Gas Hydrate, Semnan, Iran, 15 May 2013. 